\title{
Laceration Of Esophagus
}

National Cancer Institute

\section{Source}

National Cancer Institute. Laceration Of Esophagus. NCI Thesaurus. Code C50841.

A torn, ragged, mangled wound, or an accidental cut of esophagus. 